\title{
Cartas de Graciliano na França: letras autodidatas no mundo de óculos quebrados
}

[ Graciliano's letters in France: self-taught letters in the world of broken glasses

\author{
Ieda Lebensztayn ${ }^{\mathrm{I}}$
}

Este ensaio desenvolve apresentação realizada no Colóquio "Artífices da correspondência": teoria, metodologia e crítica na edição de cartas. Agradeço a gentileza de sempre de Luiza Ramos Amado, Ricardo Ramos Filho e Elisabete Marin Ribas.

RESUMO - O propósito deste artigo é, com base em cartas de Graciliano Ramos, tanto nas publicadas como em inéditas, investigar vínculos do escritor com a França. Possibilitando refletir sobre questões históricas que transparecem no trânsito de olhares estrangeiros e nacionais em relação ao Brasil e ao país europeu, as cartas deixam ver impasses e conquistas experienciados por um intelectual autodidata como o autor de Vidas secas. O diálogo epistolar com editores, voltado para o desejo recíproco de ver os romances brasileiros vertidos para a língua francesa, fala da força universal da arte fincada no fator econômico. E o olhar para o estilo das cartas, feito de humor e seriedade, apreende também das relações de amizade do escritor, com Joaquim Pinto, com Paulo Rónai, a agudez crítica, a afabilidade e o amor ao estudo das línguas e à escolha das palavras reunidas em arte. PALAVRAS-CHAVE • Graciliano Ramos; cartas; França; tradução. •

\begin{abstract}
The purpose of this essay is, based on Graciliano Ramos' letters, both published and unpublished, to investigate the writer's ties with France. Allowing to reflect on historical issues that transpire in the movement of foreign and national visions with respect to Brazil and France, the letters show the impasses and achievements experienced by a self-taught intellectual as the author of Vidas secas. The epistolary dialogue with editors, aimed at the reciprocal desire to see Brazilian novels translated into the French language, speaks about the universal force of art embedded in the economic factor. And the analysis of the style of letters, made with humour and seriousness, also captures from Graciliano's friendship relations with Joaquim Pinto, with Paulo Rónai, the critical acuteness, kindness and love devoted to the study of languages and to the choice of words assembled in art. - KEYWORDS -Graciliano Ramos; letters; France; translation.
\end{abstract}

Recebido em 8 de maio de 2017

Aprovado em 29 de julho de 2017

LEBENSZTAYN, Ieda. Cartas de Graciliano na França: letras autodidatas no mundo de óculos quebrados. Revista do Instituto de Estudos Brasileiros, Brasil, n. 67, p. I42-I64, ago. 2017.

DOI: http://dx.doi.org/Io.II6o6/issn.23I6-90IX.voi67pI42-I64

I Universidade de São Paulo (USP, São Paulo, SP, Brasil). 
E agradeço a esse alguém por não ter rasgado a minha carta: cada um de nós morre um pouco quando alguém, na distância e no tempo, rasga alguma carta nossa, e não tem esse gesto de deixá-la em algum canto, essa carta que perdeu todo o sentido, mas que foi um instante de ternura, de tristeza, de desejo, de amizade, de vida - essa carta que não diz mais nada e apenas tem força ainda para dar uma pequena e absurda pena de rasgá-la².

\section{Pressupostos hermenêuticos}

Lettre, em francês, e letter, em inglês: nas duas línguas, a mesma palavra designa carta (o papel) e letra (a escrita). Pensando no tempo das cartas manuscritas, próximo mas tão diverso do estalar deslizante de dedos das mensagens atuais, é interessante observar que tanto a carta como a letra obedecem a convenções sociais, próprias respectivamente do gênero e da língua, e têm a marca pessoal do estilo e da caligrafia, que podem incluir clareza, beleza, garranchos, o inapreensível, incompreensões.

Importa, então, conhecer traços comuns à prática epistolográfica e buscar singularidades do estilo de cada escritor-carteador - partindo sempre da leitura das cartas. Comentarei de início algumas questões teóricas e hermenêuticas, que certamente farão mais sentido à medida que eu apresentar algumas cartas de Graciliano Ramos. Um dos pressupostos de meu trabalho é o entendimento de que a teoria literária e, particularmente aqui, o estudo epistolográfico advêm do exercício de análise e interpretação dos textos. Um bom norte teórico para a análise literária me parece o caminho hermenêutico entre as partes e o todo de uma obra, compreendendo a literatura como um tripé das dimensões de construção, de expressão e de representação, além da dimensão de transitividade com o leitor. E aqui meus pressupostos críticos são os escritos de Alfredo Bosi-Reflexões sobre a artẻ Brás Cubas

2 BRAGA, Rubem. Velhas cartas; dezembro de I953. In: . A traição das elegantes. Crônicas. Rio de Janeiro:

Sabiá, I967, p. 47-8.

3 BOSI, Alfredo. Reflexões sobre a arte. 4. ed. São Paulo: Ática, I99I. 


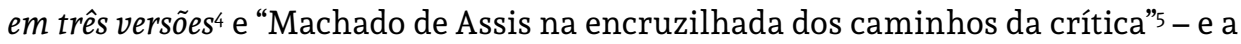
inspiração dele em Luigi Pareyson, Os problemas da estética ${ }^{6}$.

O percurso hermenêutico envolve um movimento de análise destas vertentes: a construção da obra, ou seja, a dimensão da forma (no caso de Brás Cubas, por exemplo, a "forma shandiana" inspirada em Sterne e na prosa autossatírica) - objeto de uma leitura intertextual; a expressão de conflitos subjetivos, de sentimentos, de elementos confessionais, de impasses - objeto de uma leitura existencial, moral (pense-se no "homem subterrâneo" de Machado de Assis, segundo Augusto Meyer); a representação das relações históricas e sociais - estudadas por uma leitura sociológica, que apreende da literatura melhor conhecimento da realidade (como de Astrojildo Pereira, de Roberto Schwarz). E as análises da recepção crítica das obras, como as feitas por Hélio de Seixas Guimarães a respeito de Machado de Assis7, concentram-se na transitividade com o leitor.

Cumpre reforçar que essas dimensões são indissociáveis na literatura, tanto que o estudo de cada uma delas - o viés formal, o existencial e o sociológico, fecundos em sua especificidade - demanda dialeticamente o das outras. Daí a tarefa crítica de perfazer o círculo hermenêutico entre o todo e as partes, considerando as quatro dimensões da obra de arte. Esse movimento hermenêutico de leitura constitui um exercício avesso a dogmatismos, a fórmulas preconcebidas.

- Podem-se projetar essas dimensões para o estudo de cartas, lembrando que estão amalgamadas. É, pois, fecundo ler as cartas observando estas vertentes:

- a dimensão da construção inclui a materialidade da carta, o estilo do escritor e também os chamados "arquivos da criação"; quer dizer, os diálogos epistolares apresentam bastidores da criação, de traduções de obras;

- a segunda dimensão seria a expressão subjetiva, a carta como registro de sentimentos e pensamentos das pessoas. E aqui interessa pensar também na história dos afetos, das amizades entre intelectuais, na sociabilidade de escritores, o que nos leva para a terceira vertente;

- a terceira dimensão, histórica e social, é o contexto da carta, como assunto tratado e como documento de determinado momento da história.

4 Idem. Brás Cubas em três versões. São Paulo: Companhia das Letras, 2006.

5 Idem. Machado de Assis na encruzilhada dos caminhos da crítica. Machado de Assis em Linha, ano 2, n. 4, dez. 2009.

6 PAREYSON, Luigi. Os problemas da estética. Tradução de Maria Helena Nery Garcez. São Paulo: Martins Fontes, I997.

7 GUIMARÃES, Hélio de Seixas. Machado de Assis, o escritor que nos lê. As figuras machadianas através da crítica e das polêmicas. São Paulo: Editora Unesp, 20I7; GUIMARÃES, Hélio de Seixas. Os leitores de Machado de Assis: o romance machadiano e o público de literatura no século I9. 2. ed. São Paulo: Nankin/Edusp, 2012.

8 Retomo aqui, com Marcos Antonio de Moraes, esse termo da crítica genética. Cf. DIAZ, José-Luis. Qual genética para as correspondências?. Tradução de Cláudio Hiro e Maria Sílvia Ianni Barsalini. Manuscrítica: Revista de Crítica Genética, I5, São Paulo, Associação de Pesquisadores de Crítica Genética/Humanitas, 2007, p. II9-I62; MORAES, Marcos Antonio de. Edição da Correspondência reunida de Mário de Andrade: histórico e alguns pressupostos. Patrimônio e Memória, Unesp/Assis - On-line, v. 4, p. I-I4, jun. 2009. 
Em síntese, interessa pensar na carta enquanto forma e como documento da arte, das relações interpessoais (afetos, subjetividades) e da história. Tanto a letra como a carta têm um componente social e um singular. Quanto à vertente de transitividade das obras com o leitor, leva-nos a refletir sobre a face múltipla das cartas, como meio de comunicação privada e como objeto de estudo: em sua face primeira, elas medeiam uma relação particular entre dois interlocutores; num segundo momento, podem ser fonte de conhecimento e de compreensão aos olhos de pesquisadores, organizadores e editores de correspondências e de um público vasto, necessariamente aí implicada, como em todos os campos, a dimensão ética, de respeito ao outro.

\section{Cartas de Graciliano Ramos}

A fim de apreender a vitalidade dessas questões hermenêuticas, apresentarei cartas de Graciliano Ramos, em especial algumas que permitem conhecer vínculos dele com a França. Um primeiro esclarecimento: existe o volume Cartas, publicado pela editora Record em I980, que traz a correspondência de Graciliano com familiares: os pais (Maria Amélia Ferro Ramos e Sebastião Ramos de Oliveira); as irmãs Leonor, Otacília e Marili; Heloísa, a noiva das "cartas de amor”, depois esposa (d. Ló); Luís Augusto de Medeiros, cunhado; os filhos Júnio, Clara, Ricardo Ramos e Luiza. E apenas com um amigo, Joaquim Pinto da Mota Lima Filho. Trazendo na capa o retrato de Graciliano traçado por Candido Portinari, essa edição especial reúne I03 cartas do romancista, nota de abertura escrita por Heloísa Ramos e seleção de ilustrações e notas feitas por James Amado.

Em I992, no centenário do escritor, a Record lançou a sétima edição das Cartas, com nove a mais, e esse conjunto de II2 cartas foi relançado em $20 I^{9}$. No entanto, segundo Heloísa Ramos salienta na Nota de I980, a publicação da correspondência de Graciliano, iniciada com a dessas cartas íntimas, "deve completar-se com a de cartas a amigos, escritores, críticos, editores etc." ${ }^{\text {тo }}$. Por isso, expressando sua justa consciência e generosidade em relação à importância de reunir e franquear os escritos de Graciliano aos leitores e estudiosos, Heloísa pedia, a quem possuísse mensagens do romancista, que concedesse a ela cópia e autorização para divulgá-las: "É tempo de deixar o próprio Graciliano revelar suas relações com o cotidiano e as pessoas com as quais mais de perto conviveu [...]. Os futuros estudiosos e biógrafos passam a contar com uma fonte documental direta"II.

Quanto à correspondência de Graciliano com outros intelectuais, note-se que, em

9 RAMOS, Graciliano. Cartas. Rio de Janeiro: Record, I980 (Edição especial; MPM-Comunicações). 7. ed. (aumentada). Rio de Janeiro: Record, I992. 8. ed., 20II.

Io RAMOS, Heloísa. Nota [Rio, out. I980]. In: RAMOS, Graciliano. Cartas. 8. ed. Rio de Janeiro: Record, 20II, p. 6. II Ibidem. 
2008, saiu pela Editora da Universidade Federal da Bahia o volume Cartas inéditas de Graciliano Ramos a seus tradutores argentinos Benjamín de Garay e Raúl Navarro ${ }^{\mathrm{I2}}$.

Em minha pesquisa de pós-doutorado realizada no Instituto de Estudos Brasileiros da Universidade de São Paulo - IEB/USP, financiada pela Fapesp (Processo n. 2010/I2034-9), cataloguei e transcrevi a Série Correspondência Ativa, Passiva e de Terceiros que consta do Arquivo Graciliano Ramos, doado ao IEB por Heloísa Ramos em II de outubro de I980. E desde então venho fazendo o levantamento e o registro de cartas de Graciliano dispersas em livros e em arquivos públicos e privados, agora ao lado do pesquisador e professor Thiago Mio Salla, que há tempos também se dedica a essa tarefa. Contando com a confiança e o apoio da família de Graciliano, em especial de Luiza Ramos Amado e de Ricardo Ramos Filho, que nos honram com sua amizade exemplar, o horizonte é publicarmos um volume anotado de cartas inéditas de Graciliano, com notas que ofereçam informações histórico-literárias e dados biobibliográficos dos correspondentes e das pessoas referidas. O conjunto desse material demanda atenção, sobretudo as cartas de Graciliano trocadas com outros intelectuais, ainda não publicadas. Possibilita conhecer melhor as circunstâncias históricas vividas pelo escritor (quando jovem, em Palmeira dos Índios, Maniçoba e Viçosa e na passagem pelo Rio de Janeiro; nos anos I920 e I930 em Alagoas; no período posterior à prisão, ocorrida em I936, no Rio de Janeiro), as relações afetivas e intelectuais, reflexões sobre os romances e projetos literários. Ao mesmo tempo, com seu estilo, que inclui autoironia e ternura, as cartas deixam ver o rigor ético e estético do romancista.

\section{Graciliano e A França: LETRAS E CARTAS DE HUMOR E SERIEDAdE}

No volume Cartas publicado, além das endereçadas a familiares, só há cartas para o amigo Joaquim Pinto da Mota Lima Filho. Os Mota Lima, Joaquim, Pedro, Paulo e Rodolfo, filhos do farmacêutico Joaquim, foram vizinhos e amigos de Graciliano, garotos "perfeitos" aos olhos do menino de Infância. Pedro Mota Lima escreveu romances (Coronel Lousada, I925; Bruhaha, I932; Zamor, I940; Idade da pedra, I950) e viria a ser diretor e redator de diversos jornais vinculados ao Partido Comunista, como a Tribuna Popular. Mas o Mota Lima com quem provavelmente mais se correspondeu o futuro autor de Caetés foi Joaquim Pinto, o companheiro da viagem ao Rio de Janeiro em agosto de I9I4. Numa das cartas, de Palmeira dos Índios, a 8 de fevereiro de I9I4, o jovem Graciliano, aos 2I anos, revela sua admiração pelo poeta: este compunha sonetos em francês, como "Désillusion", "Mirage", alexandrinos de um moço enamorado por uma conterrânea. E o amigo os traduzia:

I2 RAMOS, Graciliano. Cartas inéditas de Graciliano Ramos a seus tradutores argentinos Benjamín de Garay e Raúl Navarro. Introdução, ensaios e notas de Pedro Moacir Maia; organização e apresentação de Fernando da Rocha Peres. Salvador: EDUFBA, 2008. 
[...] Fiz a tradução do "Désillusion”, mas não me parece ainda apresentável. Vou modificar alguns versos, transformar a primeira estância, ver se posso fazer um trabalho digno do original. Se não tens muita pressa, posso passar com ele mais alguns dias. Agora estou numa quadra de estupidez medonha. Faz quase duas semanas que não faço nada - nunca estive tão burro ${ }^{\mathrm{T}}$.

Nesse dizer-se burro, num tom leve, do jovem, se vê a autoironia, que seria marcante em Graciliano e se liga a seu humor, rigor, ideal de perfeição e desejo de ser útil. Passado o tempo, numa carta de I948 para Jorge Amado, que estava na França e mediava o contato com editores da Tchecoslováquia, o escritor autoirônico se refere a seus romances Angústia, S. Bernardo e Vidas secas como "esses abacaxis". Sorrimos com ele: "Diga-me se devo remeter esses abacaxis agora" ${ }^{4}$.

Mas, bem antes da publicação dos romances, ainda no sertão, Graciliano já era considerado um homem de letras e lecionava francês no Colégio Sagrado Coração. A seriedade de seus estudos da língua é a base do humor com que, em carta de Palmeira dos Índios a Joaquim Pinto, a 20 de julho de I9I4, ironiza um bacharel metido a sabichão, o qual queria impor-lhe a ideia, esta sim esdrúxula, de que a palavra élite em francês seria proparoxítona. Armado do dicionário, à prova de gritos pretensiosos, o jovem intelectual já se insurgia contra uma elite bacharelesca que, afeita à superfície das palavras, está longe de ser o que há de melhor:

[...] Pela primeira vez em minha vida, parece-me, alterei-me diante de um letrado oficial: “- Isso é uma heresia, doutor, é um disparate: em francês não há vocábulos esdrúxulos”. Meti-lhe nas mãos um dicionário francês. O homem teimava: gritava que o acento do primeiro é indicava a tonicidade desta sílaba. Convenceu-se depois de meia hora ${ }^{\text {I5. }}$.

Também representativa do humor de Graciliano e com decorrências para a compreensão de relações sociais e históricas, apresento aqui uma carta inédita em livro, para a editora Gallimard, de agosto de I952. Constam do Arquivo Graciliano Ramos, no IEB, dois rascunhos manuscritos dessa carta, com alterações (indicadas entre colchetes), e uma versão datilografada, todos em francês.

I3 RAMOS, Graciliano. Carta a J. Pinto da Mota Lima Filho. Palmeira dos Índios, 8 de fevereiro de I9I4. In: Cartas, op. cit., p. 23.

I4 Idem. Carta a Jorge Amado. Rio de Janeiro, 23 de agosto de I948. Série Correspondência Ativa, Fundo Graciliano Ramos, IEB-USP.

I5 Idem. Carta a J. Pinto da Mota Lima Filho. Palmeira dos Índios, 20 de julho de I9I4. In: . Cartas, op.cit.,

p. 34 . 
Rio de Janeiro, le 8 août 1952

Librairie Gallimard

5, Rue Sébastien - Bottin

Paris (VIIe.)

France

Messieurs,

Je viens de recevoir votre lettre du $I^{\text {er }}$ août et deux exemplaires du contrat relatif à la publication de mon livre Infância, traduccion de M. Gogenheim.

J'accepte les conditions proposées e je vous renvois, suivant votre recommendation, le contrat déjà signé par M. Gallimard.

Une petite modification, Messieurs. Le contrat dit: "Rua do Curvidor - IIo - Buenos Aires Argentina". Ce n'est pas ça. Voici la véritable adresse: "Rua do Ouvidor - IIo-Rio de Janeiro - Brasil". Pas d'importance [, naturellement]. Mais [, comme nous parlons d'affaires, il faut dire que] nous ne sommes pas en Argentine. [Nous sommes brésiliens. Seulement.] Recevez, Messieurs, tous mes remerciements. Et agréez mes salutations très empressées.

\section{Graciliano Ramos ${ }^{\mathrm{I}}$.}

I6 Idem. Carta para Gallimard. Rio de Janeiro, 8 de agosto de I952. Série Correspondência Ativa, Fundo Graciliano Ramos, IEB-USP. "Senhores, Acabo de receber sua carta de $\mathrm{I}^{\circ}$ de agosto e dois exemplares do contrato relativo à publicação do meu livro Infância, tradução do Sr. Gogenheim. Aceito as condições propostas e lhes reenvio, seguindo sua recomendação, o contrato já assinado pelo Sr. Gallimard. Uma pequena modificação, Senhores. O contrato diz: 'Rua do Curvidor - по - Buenos Aires - Argentina'. Não é assim. Eis o endereço certo: 'Rua do Ouvidor - IIo - Rio de Janeiro - Brasil'. Não tem importância [, naturalmente]. Mas [como falamos de negócios, é preciso dizer que] nós não estamos na Argentina. [Nós somos brasileiros. Somente.] Recebam, Senhores, meus agradecimentos. E aceitem minhas saudações calorosas. Graciliano Ramos" (tradução minha). 
Libritic Gallimerd

Viase Jakeiro, LS avet, is

5. Bue Débratien - B.

Finia ( VIle.)

\section{Wezzieurs,}

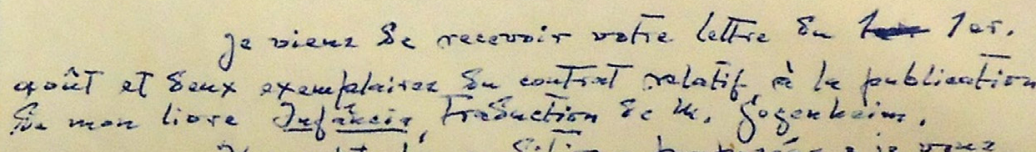

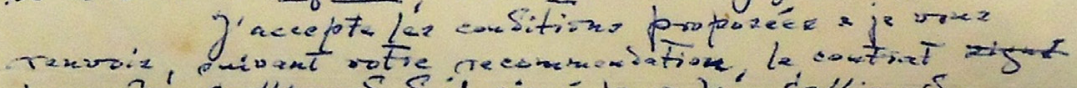

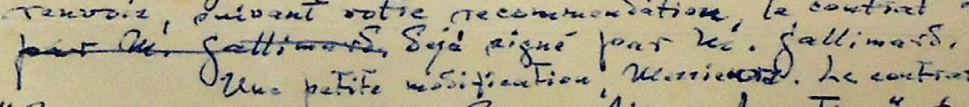

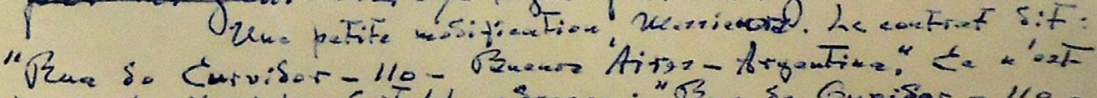

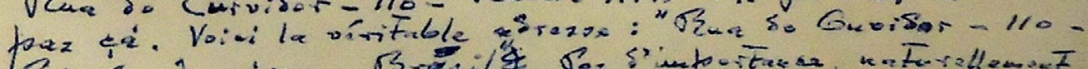

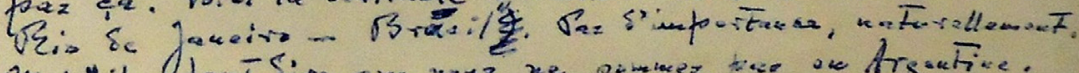

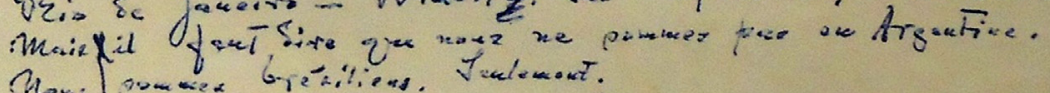

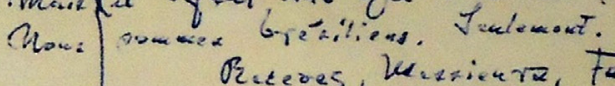

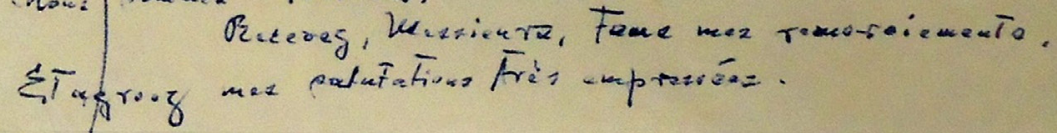

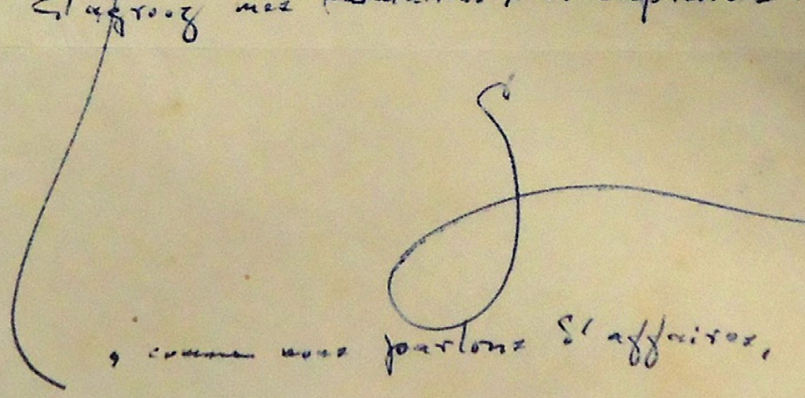




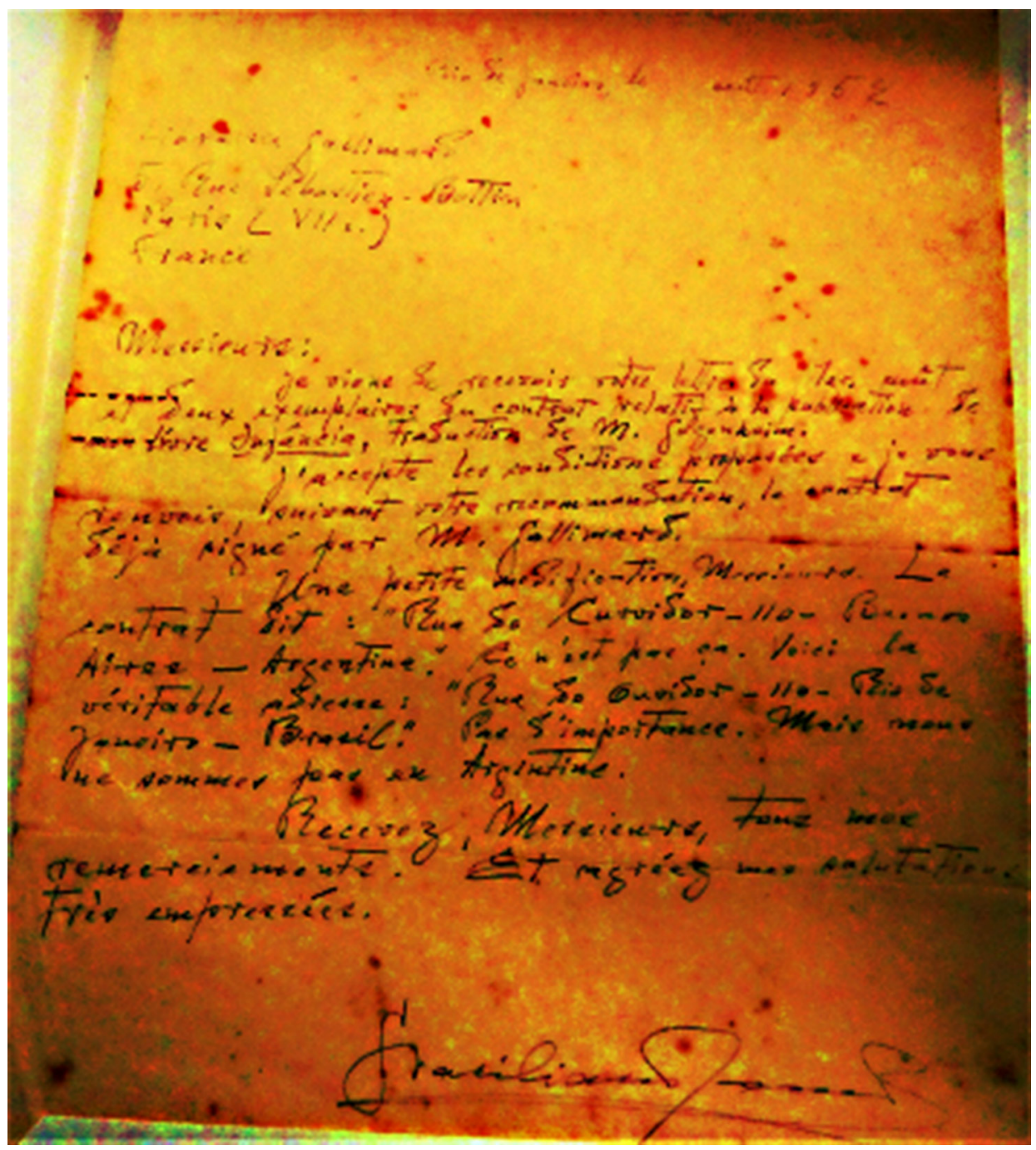

Figuras I e 2 - Rascunhos de carta de Graciliano Ramos para a Librairie Gallimard. Rio de Janeiro, 8 de agosto de I952. Série Correspondência Ativa, Fundo Graciliano Ramos, Instituto de Estudos Brasileiros, IEB/USP

Gaston Gallimard (Paris, I88I-Neuilly-sur-Seine, I975) foi um editor francês, fundador das Éditions Gallimard, que tiveram papel central para a literatura francesa do século XX. A editora Gallimard é um prestigioso grupo editorial francês, centenário, originado das edições da revista literária Nouvelle Revue Française (NRF), criada em I908 por Gallimard, André Gide e Jean Schlumberger. Em I9II Gallimard passou a dirigir as Éditions de la Nouvelle Revue Française, depois Librairie Gallimard (em I9I9) e Éditions Gallimard (em I96I). Grandes nomes da literatura francesa integraram o catálogo: o próprio Gide, Paul Claudel, Marcel Proust (cuja 
obra a princípio foi recusada por Gide na editora), Jules Supervielle, André Malraux, Antoine de Saint-Exupéry etc. ${ }^{17}$.

Retomem-se agora as questões de início sugeridas, que se concentram na materialidade ambígua de lettre como letra e carta, ambas mediadoras e dotadas de uma face pessoal e uma social. O erro das letras "Curvidor/Ouvidor" e "Buenos Aires/ Rio de Janeiro" leva a pensar na posição de Graciliano como destinatário da carta e do contrato de tradução, e a ponderar sobre a história do país de origem colonial.

Os rascunhos mostram o cuidado do romancista ao comentar, em carta para a Gallimard, que o contrato a ele enviado, referente à publicação de Infância, continha erro de letras no endereço, engano na indicação da capital e de seu país. Graciliano opta por dizer apenas que não tinha importância: ele corta os advérbios naturalmente e somente (bem irônicos, mas desnecessários para o teor objetivo da mensagem), elimina a oração causal "como falamos de negócios", de sentido óbvio, e o "é preciso dizer que”. Assim se configura seu estilo concisamente irônico: embora a indicação errada do país não afetasse nenhuma cláusula, claro que era importante constar devidamente do contrato o país de origem do escritor traduzido.

Ao se avaliar a carta tendo em vista a história pessoal de Graciliano, imagina-se que houve certo constrangimento dele, misto de respeito e indignação - afinal ele tratava de negócios e queria ver os livros traduzidos em francês. Tinha desconfiança em relação aos editores, junto com sua forte autocrítica, mas também o desejo de confiança no outro e a aposta em sua arte, para que fosse vertida para outras línguas. Apenas Angústia já tinha sido traduzido, pelo uruguaio Serafín García, em I944, e ocorreram impasses com os editores da Editorial Independencia ${ }^{\mathrm{I}}$. E, como apontarei logo mais, em I942 Graciliano já havia tratado de traduções com a Atlântica Editora, mas sem êxito, tanto que, em carta a Jorge Amado de março de I948, afirma não ter nenhum negócio para tradução em Paris.

Já ao se considerar a carta segundo uma perspectiva histórica, percebe-se o olhar dos estrangeiros em relação ao Brasil. Embora haja o interesse pela tradução da obra de Graciliano para o francês, é possível conjecturar com as palavras descuido/ descaso ou desconhecimento dos editores ou assistentes editoriais quanto aos países da América Latina de origem colonial. Daí a confusão entre Rio de Janeiro e Buenos Aires.

Como se vê, as cartas abrem para reflexões sobre as relações pessoais e históricas. Algumas crônicas de Graciliano ajudam a compreender as ambiguidades da perspectiva estrangeira, entre simpatia e ignorância, quanto ao Brasil.

I7 Cf. Encyclopédie Larousse en Ligne. Disponível em: <http://www.larousse.fr/encyclopedie/personnage/ Gallimard/IO33I2>. Acesso em: 30 abr. 20I7; ROUYER-GAYETTE, François. Gallimard, I9Io-20II: un siècle d'édition. Bulletin des Bibliothèques de France (BBF), 20II, n. 4, p. 97-98. Disponível em: <goo.gl/Ll6Nci>. Acesso em: 30 abr. 2017 .

I8 O romance saiu também em inglês (Anguish), dois anos depois, com tradução de Lewis C. Kaplan, tendo sido amistosa a relação com os editores da A. A. Knopf, segundo revelam uma carta de Graciliano de I944 e a conhecida história de empenho editorial do casal Blanche e Alfred Abraão Knopf, de Nova York. 


\section{JibOIAS NA RUA, RÓTULOS NA ESTANTE}

Estampada no Diário de Notícias do Rio de Janeiro a 2 I de novembro de $1937^{\text {I9 }} \mathrm{e}$ incluída no volume Linhas tortas, "Jiboias" traz a ironia bem-humorada de Graciliano em relação ao sem sentido de certo olhar estrangeiro para a realidade do Brasil, em que crianças brincariam nas calçadas com diamantes e as pessoas conviveriam docemente com jiboias. Graciliano ironiza o fato de uma "amável senhora francesa (ou belga)" haver publicado, em um jornal carioca, que as jiboias aqui seriam animais domésticos de grande utilidade: "vigiam as casas, comem os ratos, brincam com as crianças, enfim, substituem perfeitamente os cães, os gatos e as amas-secas"20.

Repudiando as falsificações, nesse caso as veiculadas pela imprensa, o escritor aproveita a imagem das jiboias como metáfora dos poderosos do país, dos donos do dinheiro, dos governantes, de forma a ressaltar criticamente a prática predatória desses proprietários e, assim, o estereótipo do brasileiro como cordial, o qual serve para naturalizar, disfarçar e perpetuar a exploração e a violência.

Não, senhora. Essa história está mal contada. No gênero jiboia não existem no Brasil bichos úteis - nem as jiboias verdadeiras nem as outras, as da indústria, da finança, da política etc. [...] Aliás a afirmação muito repetida de que somos uma gente macia, de coração mole, desacreditou-se ${ }^{2 r}$.

Mas, se Graciliano contesta a visão estrangeira do Brasil como exótico, pitoresco ou terra de gente dócil, seu olhar crítico se dirige também para a ignorância nacional, em especial para a falta de tradição de leitura no Brasil. Embora considerando a existência de "excelentes romances" brasileiros, o autor de Vidas secas entendia que a necessidade de "exportar literatura" convivia com a preferência por livros franceses, com a desconfiança ante o produto nacional. Em "Romances", publicado no Diário de Notícias a 3 de julho de I938, a sugestão irônica do escritor é exportar a ficção nacional, já que pouca gente a lê, e importá-la vertida para a língua francesa. Ele ironiza certa preferência “indígena”, nacional, acrítica, pelo estrangeiro tão só por ser estrangeiro. Sobressai a consciência de Graciliano quanto ao aspecto material do livro, mercadoria que poderia ser alvo da tão corriqueira contrafação, como o feijão bichado ou a banha com água, vendidos conforme o "bom processo" do fabricante, "a intrujice de apresentar o artigo indígena com rótulo estrangeiro":

Evidentemente, apesar do otimismo reinante, não temos livros exportáveis. Mas poderíamos vender alguns para fora e depois comprá-los de novo, exatamente como fazemos com certos produtos, que saem daqui e voltam melhorados, empacotados e recomendados por uma gente qualquer, que julgamos superiores.

I9 Cf. SALLA, Thiago Mio. Graciliano Ramos e a Cultura Política: mediação editorial e construção do sentido. São Paulo: Edusp/Fapesp, 20I6, p. 532.

20 RAMOS, Graciliano. Jiboias. In: . Linhas tortas. I4. ed. Rio de Janeiro: Record, I989, p. I66.

2I Ibidem, p. I67. 
Os romances brasileiros custam uma ninharia e envelhecem nas prateleiras dos editores. Os romances franceses estão pela hora da morte e são procurados com avidez. O governo, se se ocupasse com isso, mandaria passar algumas novelas indígenas para o francês. Talvez elas não fossem vendidas lá fora. Não faria mal. Viria para aqui a tiragem toda. Vendo-as em línguas de branco, o público arregalaria o olho, convencerse-ia de que estava diante de mercadoria boa e cairia no logro: daria vinte mil-réis por uma brochura que aqui se vende por seis ${ }^{22}$.

Dessa forma, o que desagrada a Graciliano é o olhar acrítico e deslumbrado, sem observação realista, de franceses em relação ao Brasil e vice-versa. A crítica de Graciliano à ignorância dos estrangeiros e dos próprios brasileiros em relação à realidade do país é a base do humor da carta e das crônicas referidas. Merecem riso tanto a imagem de um Brasil exótico como a admiração subserviente, por modismo sem conhecimento de causa, ao estrangeiro.

\section{O ASTRÔNOMO SE EMBRENHA NAS LETRAS FRANCESAS}

Por outro lado, longe de um apego automático, superficial, pelo estrangeiro, a formação intelectual de Graciliano - em que teve peso a cultura da França, de acordo com a história do país colonizado - e também seu gosto pessoal lhe definiram a fascinação e o entusiasmo pela literatura francesa, conforme declarou num depoimento ao jornal Dom Casmurro, do Rio de Janeiro, de 23 de dezembro de 1937.

Sobressai desse depoimento um diagnóstico da educação no Brasil e da condição dos intelectuais. Graciliano se refere às dificuldades que as crianças experimentavam por serem Os Lusíadas o primeiro livro que lhes vinha às mãos:

Em tal circunstância, só há um recurso: refugiar-se na literatura francesa. Comigo, foi assim. [...] A língua francesa, direta, facilita os autodidatas, que somos todos nós, intelectuais brasileiros. Em pouco, familiarizei-me principalmente com os romancistas. Balzac foi para mim um deslumbramento. Ainda hoje me detenho diante de sua obra com a certeza de que me encontro com o maior romancista do mundo.

[...] Depois, Zola impressionou-me também, mas não conseguiu desviar a fascinação pela obra balzaquiana. Julgo ter sido verdadeiramente diabólica a mentalidade do autor das Ilusões perdidas. A propósito, acho que é este o seu melhor livro. Que surpresa de técnica! Ali há de tudo, desde a base econômica, admiravelmente definida e levantada, e sobre a qual o resto do livro cai, para consistência eterna. O resto do livro caminha impulsionado por aquela rajada até à surpresa daqueles pensamentos filosóficos que Balzac coloca na boca de um cura. Por isso, bastava apenas Balzac para que eu amasse intensamente a França.

22 Idem. Romances. In: . Linhas tortas, op. cit., p. I42. 
O escritor português que me deixou maior influência foi, em parte, francês: Eça de Queirós. O seu ritmo, a sua construção, o seu riso - tudo teve o seu berço sob o solo de Paris, muito embora ele construísse os seus volumes num hotel de Londres ou mesmo na ambiência sossegada de Leiria ${ }^{23}$.

A primeira questão a se salientar é o autodidatismo. Também em Infância (I945) se lê que, "aos sete anos, no interior do Nordeste, ignorante da [sua] língua”, o menino Graciliano foi obrigado a ler Camões, a adivinhar Camões ${ }^{24}$. Uma das soluções foi o refúgio na literatura francesa. Então vem esta afirmação incisiva de Graciliano: a língua francesa, direta, "facilita os autodidatas, que somos todos nós, intelectuais brasileiros”. Nessa questão do autodidatismo, identifica-se o problema da educação do país e, ao mesmo tempo, vislumbram-se possibilidades, ainda que pessoais e remotas, de minorá-lo, por meio da combinação de esforço, estudo, paciência e talento. Recorde-se aqui o capítulo "Os astrônomos", de Infância, inspiração para apreender a imagem de Graciliano como astrônomo do inferno.

Quase analfabeto aos 9 anos, experienciou noites extraordinárias de leitura ao lado de seu pai, porém sucedidas pela sensação de ruína quando o pai abandonou o novo hábito. Eis que, aconselhado pela prima Emília, o menino se descobriu capaz de ser como os astrônomos, que leem o céu. Ele podia reunir em palavras as letras conhecidas e ler a narrativa sobre crianças abandonadas: sempre há o inapreensível, mas o que se conhece lança fecunda luzinha de entendimento em meio às trevas da realidade. Condensado nessa imagem do astrônomo do inferno, o autodidatismo constitui um caminho ético de conhecimento e compreensão do valor singular e interdependente de cada letra, palavra, coisa, ser, possibilitando emergir a luz dos estigmatizados como incapazes.

Fica essa questão do autodidatismo, com seus impasses de origem e potencialidades, para se pensar, também, quanto à formação de outros intelectuais brasileiros, como Machado de Assis, de escritores franceses e de outros países, como o tradutor e crítico húngaro naturalizado brasileiro Paulo Rónai, de que tratarei adiante. Quanto ao aprendizado autodidata, é interessante notar que, em carta de 7 de fevereiro de I9I3 para Joaquim Pinto, um ano antes daquela sobre a tradução de sonetos do amigo, Graciliano se queixava do francês, "língua miserável inventada pelo diabo para tormento dos infelizes como eu”. Insatisfeito, não lhe servindo então o método de Brunswick, oferece-se para trocá-lo temporariamente pelo Pereira do interlocutor.

Autor do Curso de língua francesa - método de Ahn reformado (publicado no Porto pela Livraria Chardron, de Lello \& Irmão, oitava edição em I9I2), além do Curso

23 DE GRACILIANO Ramos. In: RAMOS, Graciliano. Conversas. Org. Thiago Mio Salla e Ieda Lebensztayn. Rio de Janeiro: Record, 2014, p. 282.

24 "Aos sete anos, no interior do Nordeste, ignorante da minha língua, fui compelido a adivinhar, em língua estranha, as filhas do Mondego, a linda Inês, as armas e os barões assinalados. Um desses barões era provavelmente o de Macaúbas [...]. Deus me perdoe. Abominei Camões. E ao Barão de Macaúbas associei Vasco da Gama, Afonso de Albuquerque, o gigante Adamastor, barão também, decerto." RAMOS, Graciliano. O barão de Macaúbas. In: . Infância. 3. ed. Rio de Janeiro: José Olympio, I953, p. I23. 
de língua espanhola, do Dicionário de sinônimos da língua portuguesa, entre outros, Henrique Brunswick (I846-I9I9) foi também revisor do livro de Jacob Bensabat significativamente intitulado $O$ francês sem mestre, em 50 lições: novo método popular, adaptado ao uso dos portugueses e dos brasileiros. Já o Pereira referido por Graciliano deve ser Joaquim Gonçalves Pereira, cuja obra igualmente se destina a autodidatas: $O$ mestre popular aperfeiçoado ou o francês sem mestre ao alcance de todas as inteligências $e$ de todas as fortunas, etc., editado em Coimbra, provavelmente em I878 ${ }^{25}$. Lembre-se que o esforço autodidata permitiu a Graciliano, tempos depois, traduzir A peste, de Albert Camus (publicado pela José Olympio em I950), como também, do inglês, Memórias de um negro, de Booker T. Washington (editado pela Companhia Editora Nacional em I940) ${ }^{26}$.

Quanto ao idioma italiano, segundo Graciliano escreve jocosamente para o amigo em I9I3, não o estudava mais, pois já sabia muito, "mais até do que era preciso saber". E aqui vem à mente a (auto)ironia aos cursos de italiano do sertão nordestino, cujos mestres prescindiam do domínio da língua: bastava arrumar one ou ine no fim das palavras para abrir uma escola e logo ter concorrência. "E se aparecer por aí um carcamano, adoeço e perco a fala” ${ }^{2}$. Ao lado da crítica de Graciliano à terra de professores improvisados, cuja necessidade muitas vezes leva a ensinarem antes de aprenderem, sobressai a motivação de seu desejo de haver estudado italiano: ler Dante. Graciliano relatou tal fato em entrevista para a Folha da Manh $\tilde{a}^{28} \mathrm{em}$ I949, e também o sublinhou Otto Maria Carpeaux ${ }^{29}$, outro autodidata da língua portuguesa, este graças a leituras de Machado de Assis e à ajuda de Aurélio Buarque de Holanda.

Em sua liberdade para além de cerceamentos institucionais, já se vê como o motor e a força do autodidatismo são o desejo de conhecimento e o prazer da literatura. "Pessoas dando prazer com palavras impressas": tal definição de escritor, por Stendhal ${ }^{\circ \circ}$, é evocada por Brigitte Diaz justamente em sua reflexão sobre o sentido

25 Cf. UNIVERSIDADE DO PORTO. Faculdade de Letras. Biblioteca Digital. Disponível em: 〈goo.gl/YjP7OP >. Acesso em: 30 abr. 2017.

26 Quanto à tradução francesa, confira-se: BICALHO, Ana Maria. Diálogos interculturais: Graciliano Ramos tradutor/traduzido. Tese (Doutorado em Letras e Linguística). Universidade Federal da Bahia, Instituto de Letras, Salvador, 2010.

27 RAMOS, Graciliano. Professores improvisados. Revista de Ensino, Órgão Oficial do Departamento Geral da Instrução Pública de Alagoas. Maceió: Imprensa Oficial, ano III, n. I7, pp. 44-5, set./out. I929; In: .Viventes das Alagoas. I9. ed. Rio de Janeiro: Record, 2007.

28 AFIRMA Graciliano Ramos: “Não me considero um escritor". Folha da Manhã, São Paulo, 25 set. I949, p. 35, apud RAMOS, Graciliano. Conversas, op. cit., p. 22I.

29 CARPEAUX, Otto Maria. Graciliano Ramos (No sétimo dia de sua morte). Correio da Manhã, Rio de Janeiro, 27 mar. 1953.

30 STENDHAL. Vies de Haydn, de Mozart et de Métastase. Révision du texte et préface par Henri Martineau Paris: Le Divan, I8I4. Disponível em: <http://gallica.bnf.fr/ark:/I2I48/bpt6k6945I/fr.image.r=>. Acesso em: 25 jul. 2017. 
nômade, inclassificável, do gênero epistolar, como da literatura contrária à postura de literato oficial ${ }^{3 \text {. }}$.

Assim, a segunda questão a ressaltar é o gosto de Graciliano por Balzac: "Balzac foi para mim um deslumbramento [...] bastava apenas Balzac para que eu amasse intensamente a França" ${ }^{2}$. Observem-se o substantivo - deslumbramento -, o verbo e o advérbio - amasse intensamente: os termos enfáticos escolhidos pelo autor expressam a forte admiração que lhe despertava o criador da Comédia humana, e aqui não se trata de um fascínio superficial pelo estrangeiro, mas de um "deslumbramento" embasado em leituras e em uma concepção de realismo artístico. Evidenciando os motivos de tal predileção, sobretudo a coerência da construção dos romances de Balzac, Graciliano exalta a "surpresa de técnica", a "base econômica, admiravelmente definida e levantada", que garante a "consistência eterna" de um romance como Ilusões perdidas (I837). Nesse sentido, e pensando na questão das traduções e, portanto, da universalidade das obras - objeto aqui abordado a partir das cartas -, interessa retomar o artigo "O fator econômico no romance", publicado n' O Observador Econômico e Financeiro, do Rio de Janeiro, em abril de I937, e com o título "O fator econômico no romance brasileiro" na Tribuna Popular, do Rio de Janeiro, a I7 de julho de I945. Nesse artigo, Graciliano também destaca a base econômica sobre a qual se move "a sociedade balzaquiana, políticos, nobres, jornalistas, militares, negociantes, prostitutas e ladrões, tipos vivos que ainda nos enchem de admiração"33. Agradam a Graciliano o vínculo dessas figuras com a realidade e sua quase atualidade, apesar de afastadas de nós, "de se haverem iluminado com velas de cera e viajado em diligências"34. Justamente essas distâncias e proximidades temporais, espaciais e linguísticas são centrais para se ponderar sobre as traduções. Refletir sobre a particularidade e a universalidade das obras leva a retomar as considerações sobre a arte feitas inicialmente neste ensaio, que envolve, pensando aqui em Graciliano, a construção depurada da forma, do estilo preciso, agudo, a representação social crítica e a expressão de sofrimentos. Ou seja, a arte literária, com sua forma singular, capaz de figurar em palavras situações da realidade, de criar consciência e de comover, atinge universalidade.

No mencionado artigo "O fator econômico no romance brasileiro", Graciliano critica os romancistas que, "simulando horror excessivo ao regional, [...] pretendem tornar-se à pressa universais”35. Sábias, são clássicas as palavras do escritor: “Para sermos completamente humanos, necessitamos estudar as coisas nacionais, estudá-las de baixo para cima. [...] Acho que o artista deve procurar dizer a verdade.

3I Cf. DIAZ, Brigitte. O gênero epistolar ou o pensamento nômade: formas e funções da correspondência em alguns percursos de escritores no século XIX. Tradução de Brigitte Hervot e Sandra Ferreira. São Paulo: Edusp, 20I6, p. 246. Enriquecendo a bibliografia em língua portuguesa sobre cartas, confira-se também outra recente tradução: HAROCHE-BOUZINAC, Geneviève. Escritas epistolares. Tradução de Ligia Fonseca Ferreira. São Paulo: Edusp, 2016.

32 DE GRACILIANO Ramos. In: RAMOS, Graciliano. Conversas, op. cit., p. 282.

33 RAMOS, Graciliano. $\mathrm{O}$ fator econômico no romance brasileiro. In: . Linhas tortas, op. cit., p. 247.

34 Ibidem.

35 Ibidem, p. 250. 
Não a grande verdade, naturalmente. Pequenas verdades, essas que são nossas conhecidas" ${ }^{36}$.

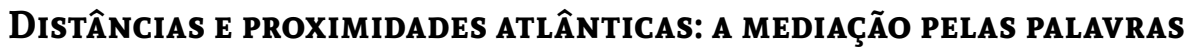

Graciliano Ramos apostava na tradução e na universalidade de sua obra, construída com base na singularidade das coisas nacionais. Houve uma tentativa nos anos 1940 de publicar versões de seus romances em francês pela Atlântica Editora, como se vê na correspondência com Charles Ofaire. Representante suíço da Atlântica Editora instalado no Rio de Janeiro, Charles Ofaire (Karl Hofer) foi o editor de Georges Bernanos no Brasil, durante a Segunda Guerra Mundial; o primeiro a publicar Monsieur Ouine (romance finalizado em Pirapora, em I94I), Lettre aux Anglais (I942) e Le Chemin de la Croix-des-Âmes (quatro volumes, I943-I945). Editou também Minha vida de menina, de Helena Morley, em I942; e Mémoires d'un sergent de milices, versão de Paulo Rónai, em I944. Ofaire foi representante oficial da Enciclopédia Francesa e diretor, no Rio de Janeiro, do Centro de Edições Francesas ${ }^{37}$. Por causa da guerra, havendo diminuído aqui a importação de livros franceses e crescido a de obras americanas e inglesas, a Atlântica Editora passou a produzir, no Brasil, livros franceses e traduções, e programou verter para o francês uma série de brasileiros, como Machado de Assis, Aluísio Azevedo, Raul Pompeia, além dos contemporâneos Graciliano, José Lins do Rego, Rachel de Queiroz. Em setembro de I942, o jornal Dom Casmurro indicou “Uma interessante iniciativa editorial": novidade na história literária, os tradutores da Atlântica trabalhariam em contato constante com os autores, consultando-os diante de brasileirismos, modismos, expressões regionais, a fim de garantir a fidelidade das versões ${ }^{3}$.

Leia-se esta carta de Graciliano a Charles Ofaire, escrita a 26 de agosto de I942:

36 Ibidem, p. 252.

37 Cf. SODRÉ, Muniz. Georges Bernanos e o Brasil. A França no Brasil. Fundação Biblioteca Nacional, 2009. Disponível em: 〈goo.gl/IRNLU5>. Acesso em: 7 maio 20I7; SUPPO, Hugo Rogelio. La politique culturelle française au Brésil entre les années I920-I950. Tese (Doutorado). Villeneuve d’Ascq, França: Presses Universitaires du Septentrion, 2000. 3 v. O Centro de Edições Francesas e as Éditions Desclée de Brouwer publicaram em português e em francês, em I942, em Bruges (Bélgica), o livro infantil O circo, escrito e ilustrado por Santa Rosa. Em carta a Heloísa, de 3 de março de I937, Graciliano comenta serem maravilhosos os desenhos de Santa do circo de cavalinhos. De fato, o livro venceu em I939 um concurso do Ministério da Educação.

38 Cf. A AMÉRICA lê livros franceses impressos no Brasil. Diário Carioca, seção Homens, Livros e Ideias, Rio de Janeiro, 4 out. 1942; UMA INTERESSANTE iniciativa editorial. Dom Casmurro, Rio de Janeiro, 12 set. 1942, p. 6. 
Ilmo. Sr.

Charles Ofaire

Atlântica Editora

Prezado Senhor:

Recebi, por intermédio do nosso amigo Prof. Paulo Rónai, a carta em que V. S. me comunica haver resolvido publicar em francês uma série de romances brasileiros.

Agradeço-lhe a escolha que fez para ela dos meus livros Angústia, S. Bernardo e Vidas secas. Quanto aos direitos de tradução, poderemos fixá-los em um ano, se V. S. achar este prazo conveniente.

Disseram-me há tempo que certa senhora francesa, ou belga, tinha traduzido Vidas secas, ou desejava traduzi-lo. Como há falta de tradutores, segundo ouvi quando nos conhecemos, trago-lhe esta informação. Caso ela seja útil, procurarei descobrir a referida senhora e apresentá-la ao Prof. Paulo Rónai.

Renovando os agradecimentos que manifestei, subscrevo-me, com elevada estima e consideração,

\section{Graciliano Ramos 39}

Também na correspondência passiva de Graciliano existem cartas da Atlântica Editora: numa de I945 a editora se oferece para negociar os direitos de tradução com editores, por intermédio de correspondentes na Argentina, nos Estados Unidos, na Inglaterra e pelo escritório que abririam em Paris. Além disso, consta do Arquivo do IEB um contrato de publicação de S. Bernardo, de 2 I de outubro de I944. E uma notícia publicada em 26 de janeiro de I945 em A Manhã, do Rio de Janeiro (p. 3), comunicava que "A Atlântica Editora já havia contratado tradutores para a versão francesa dos romances de José Lins do Rego, Graciliano Ramos, Rachel de Queiroz e Jorge Amado”.

Mas, apesar de todo esse contato com a Atlântica nos anos I940, em carta de Paris para José Olympio, de I952, Graciliano afirma supor que em breve teria por aquelas "bandas" alguns livros traduzidos ${ }^{40}$. Isso ainda demoraria alguns anos: o primeiro livro de Graciliano em francês foi Infância, que saiu em I956 pela Gallimard, conforme o contrato mencionado naquela carta da rua do "Curvidor". Vejam-se as referências das versões da obra de Graciliano Ramos na França, publicadas inicialmente pela Gallimard, na coleção La Croix du Sud, dedicada à América Latina, e depois coleção Du Monde Entier (o autor havia falecido em I953):

- Infância, em I956: Enfance, mémoires. Tradução de G. Gougenheim. Coleção La Croix du Sud. Nova edição em I99I, Coleção Du Monde Entier;

39 RAMOS, Graciliano. Carta a Charles Ofaire. Rio de Janeiro, 26 de agosto de I942. Série Correspondência Ativa, Fundo Graciliano Ramos, IEB-USP.

40 SORÁ, Gustavo. Brasilianas: José Olympio e a gênese do mercado editorial brasileiro. São Paulo: Edusp: Com-Arte, 20Io, p. 264 . 
- Vidas secas, em I964: Secheresse. Tradução de Marie-Claude Roussel. Coleção La Croix du Sud. Nova edição em I989. E em 20I4: Vies arides. Tradução de Mathieu Dosse. Prefácio de Michel Riaudel. Paris: Chandeigne. Coleção Bibliothèque Lusitane;

- S. Bernardo, em I986, com tradução de Geneviève Leibrich. Coleção L'Imaginaire;

- Memórias do cárcere, em I988: Mémoires de prison. Tradução, prefácio e notas de Antoine Seel e Jorge Coli. Coleção Du Monde Entier;

- Angústia, em I992: Angoisse. Tradução de Nicole Biros e Geneviève Leibrich. Coleção Du Monde Entier;

- Insônia, em I998: Insomnie: nouvelles. Paris. Tradução de Michel Laban. Coleção Du Monde Entier.

\section{O PARTILHAR DO “ARRANJO DE NINHARIAS”}

Cumpre destacar a amizade de Graciliano Ramos com Paulo Rónai, mencionado na carta a Ofaire como mediador para as traduções em francês. No "Discurso de Graciliano Ramos", de 27 de outubro de I942, quando completou 50 anos e foi homenageado no restaurante Lido, em Copacabana, o autor de Angústia se referiu ao fato de se encontrarem então no Rio de Janeiro os amigos Aurélio Buarque, José Lins do Rego e ele próprio, nordestinos migrados para o Sul (ele à força, preso), mais Otto Maria Carpeaux e Paulo Rónai, ambos fugidos da Guerra na Europa.

[...] Os acontecimentos forçaram-me a deslocações imprevistas. Julgo que se dá isso com toda gente. Há dez anos, na Europa central, Otto Maria Carpeaux e Paulo Rónai andavam pelas universidades e não sonhavam percorrer e estudar um dia a nossa terra e a nossa literatura. [...] As encrencas da Europa lançaram Paulo Rónai e Otto Maria Carpeaux no Rio de Janeiro, onde estes mestres aplicam a sua cultura numa análise fria do material que lhes fornecemos. José Lins do Rego tinha no espírito banguês, canaviais, bagaceiras e casas-grandes. Deu à luz uma região do Nordeste [...]. Aurélio Buarque de Holanda possuía uma avó indefinível - d. Cândida Rosa. Aurélio definiu-a em dois trabalhos, fixou-lhe rigorosamente a língua e a figura. [...] e consertou um dicionário [...]. E aí temos a guerra, os engenhos e d. Cândida Rosa influindo na existência de alguns indivíduos, fazendo que eles imaginassem deliberar conhecer de perto Copacabana e a rua do Ouvidor ${ }^{4}$.

Paulo Rónai (Budapeste, I907-Nova Friburgo, I992) aprendeu português de forma autodidata, vertendo poemas para o húngaro. Se Graciliano traduziu sonetos do amigo Joaquim Pinto, do francês, o primeiro livro em português que Rónai leu foi $A s$ cem melhores poesias líricas da língua portuguesa, de Carolina Michaëlis. Professor de latim e de italiano num ginásio de Budapeste, ele encomendou da livraria Perche, de Paris, tal antologia. Nas férias de Natal, o livro lhe chegou às nove da manhã, e, às dez, ele já possuía o único dicionário de português, para o alemão, de Luísa Ey, das

4I RAMOS, Graciliano. Discurso de Graciliano Ramos. In: . Garranchos. Textos inéditos de Graciliano

Ramos. Organização de Thiago Mio Salla. Rio de Janeiro: Record, 20I2, p. 208-209. 
livrarias de Budapeste. Às três da tarde, Antero de Quental tinha seu soneto "Sonho oriental” em versos húngaros; às cinco, a tradução estava aceita por uma revista ${ }^{42}$.

"Alegre e doce como um idioma de passarinhos": assim é o português, dissera a Rónai o escritor húngaro Desidério Kosztolányi. Outra bela e interessante imagem, para o futuro crítico naturalizado brasileiro, a língua portuguesa, que ele só conhecia escrita, parecia um latim falado por crianças ou velhos, por gente que não tivesse dentes. Isso porque várias palavras perderam consoantes, como lua (luna), dor (dolor), pessoa (persona), veia (vena), as quais ele olhava com espanto.

Por causa das traduções de poemas brasileiros, Paulo Rónai trocou cartas com o poeta Ribeiro Couto, então cônsul na Holanda. E em I939, quando foi deflagrada a guerra, ele publicou a antologia Mensagem do Brasil: os poetas brasileiros da atualidade (Brazilia üzen: Mai Brazil költök), tradução para o húngaro de poemas de Carlos Drummond de Andrade, Cassiano Ricardo, Cecília Meireles, Jorge de Lima, Manuel Bandeira, Mário de Andrade, entre outros. Em I94I, fugindo de um campo de concentração, Rónai chegou ao Brasil - conforme Graciliano ressalta no referido "Discurso".

E justo o encontro de Rónai com um conterrâneo e amigo de Graciliano - Aurélio Buarque - significou fecundo vínculo afetivo e intelectual: desde as trocas de aulas de português e de latim até os mais de 30 anos selecionando e traduzindo contos, transbordou em obras como o Mar de histórias, antologia do conto mundial publicada originalmente pela José Olympio, em nove volumes, de I945 a I963.

Assim, o olhar para a correspondência com editoras francesas possibilita perceber impasses dos países europeus e dos países de origem colonial. Mas permite também destacar a história pessoal de intelectuais como Graciliano Ramos e Paulo Rónai: os dois amigos foram autodidatas, admiradores da literatura francesa, experienciaram injustiças e sofrimentos (prisão, guerra) e se empenharam pela arte e seu potencial de tradução e compreensão a partir do respeito aos homens em suas semelhanças e diferenças.

Tanto Graciliano como Paulo Rónai eram admiradores da literatura francesa: este veio a coordenar a tradução dos 89 livros da Comédia humana, cuja construção, com o "fator econômico", o romancista brasileiro apreciava. E aqui evoco outro episódio das relações de Graciliano com a França que tem sua graça (embora algo dramático): em carta, de Praga, de 28 de abril de I952, para "Minha gente”, os filhos, Graciliano conta que não podia escrever porque estava "sem ver as letras"; tinha quebrado os óculos em Paris. Avisa que dona Ló contaria as "aventuras" deles naquelas "civilizações”. E o IEB-USP guarda essa carta de Heloísa, dirigida a "Meus queridos brotinhos" e reveladora da emoção de Graciliano em Paris, palco de escritores que ele tanto admirava:

Não sei mesmo o que menos impressiona. Desde Montaigne ao nosso Danton, Anatole, Balzac, Zola, Vitor Hugo, temos a impressão de que vamos a qualquer momento encontrá-los na rua. Tão viva é Paris. O nosso hotel fica à margem do Sena, no cais

42 Essas informações se encontram em: RÓNAI, Paulo. Como aprendi o português. In: Como aprendi o português e outras aventuras. Rio de Janeiro: Casa da Palavra; Fundação Biblioteca Nacional, 20I3. 
Anatole France. Todo o Sena tem quarteirões com nomes de franceses ilustres e em cada rua lemos em placas de bronze ou mármore nomes de heróis franceses, mortos em combate na última guerra. Grace está sonhando e não quer perder uma hora passada em Paris. Disse agora que não está emocionado, mas que pode morrer a qualquer hora pois realizou o que sonhara aos onze anos ${ }^{43}$.

Esse sonho realizado, emoção clássica de Graciliano em Paris, fala da força local e universal da arte, a qual ele também atingiu, como sintetizam suas palavras sobre Vidas secas em carta ao tradutor argentino Benjamín de Garay, de I3 de dezembro de I937: "O meu bárbaro pensamento é este: um homem, uma mulher, dois meninos e um cachorro, dentro de uma cozinha, podem representar muito bem a humanidade. E ficarei nisto, enquanto não me provarem que os arranha-céus têm alma"44.

E o crítico literário Paulo Rónai partilha com Graciliano precisão e originalidade na maneira como traduz as faces material e universal que constroem o drama dos sertanejos em Vidas secas: "Em cada instante eles [Fabiano e família] estão com a sua vida inteira no espírito e nos olhos. Por isso o escritor representou essas vidas secas num quadro contínuo, único, de que ele passa a iluminar ora este ora aquele setor”45.

Tendo alimentado, na Europa, "sôfrega curiosidade"46 pela poesia das palavras brasileiras, justo no Brasil Rónai pôde sobreviver à guerra e frutificar seu "amor ao esforço intelectual"47. Também Graciliano resistiu a injustiças por meio da “obstinação concentrada" ${ }^{8}$ no arranjo de palavras, dedicando-se aos romances. Exemplares, sobressaem esses dois intelectuais, que privilegiaram o respeito pelas palavras e pelas pessoas, deixando ver a verdade dos afetos, como nesta confissão de Rónai:

43 RAMOS, Heloísa. Carta para os filhos. Paris, 24 de abril de I952. Série Correspondência de Terceiros, Fundo Graciliano Ramos, IEB-USP.

44 RAMOS, Graciliano. Carta a Benjamín de Garay. Rio de Janeiro, I3 dez. I937. In: . Cartas inéditas de Graciliano Ramos a seus tradutores argentinos Benjamín de Garay e Raúl Navarro, op. cit., p. 69.

45 RÓNAI, Paulo. O mundo de Graciliano. Correio da Manhã. Rio de Janeiro, 6 de junho de I948, pp. 2-3; RÓNAI, Paulo. No mundo de Graciliano Ramos. In: Encontros com o Brasil. Rio de Janeiro: Instituto Nacional do Livro, I958, p. I08.

46 Idem. Como aprendi o português. In: . Como aprendi o português e outras aventuras, op. cit., p. 22.

47 Idem. Uma geração sem palavras. In: Como aprendi o português e outras aventuras, op. cit., p. 88.

48 "[...] É uma obstinação concentrada, um longo sossego que os fatos exteriores não perturbam. Os sentidos esmorecem, o corpo se imobiliza e curva, toda a vida se fixa em alguns pontos - no olho que brilha e se apaga, na mão que solta o cigarro e continua a tarefa, nos beiços que murmuram palavras imperceptíveis e descontentes. Sentimos desânimo ou irritação, mas isto apenas se revela pela tremura dos dedos, pelas rugas que se cavam. Na aparência estamos tranquilos. Se nos falarem, nada ouviremos ou ignoraremos o sentido do que nos dizem. E como há frequentes suspensões no trabalho, com certeza imaginarão que temos preguiça. Desejamos realmente abandoná-lo. Contudo gastamos uma eternidade no arranjo de ninharias, que se combinam, resultam na obra tormentosa e falha." RAMOS, Graciliano. Manhã. In: Infância, op. cit., p. 2I (grifos meus). 
Sempre me faltou coragem para escrever sobre Graciliano Ramos. Sua obra me comunicou emoções muito diretas, e sinto constrangimento em falar no que tenho de tão íntimo. Por outro lado, o exemplo do romancista leva a gente a empregar as palavras com muita cautela, a desconfiar dos epítetos, a abafar o enternecimento e a admiração49.

Assim, as letras possibilitam ao escritor firmar-se no "arranjo de ninharias", etimologicamente "criancices", da língua portuguesa, latim sem dentes, de velhos, crianças, passarinhos. E os óculos quebrados em Paris relembram a luz da cegueira antiga: na escuridão, Graciliano contribui para que se compreenda "o valor enorme das palavras".

\section{SOBRE A AUTORA}

IEDA LEBENSZTAYN é pesquisadora na

Biblioteca Brasiliana Mindlin-FFLCH/USP, bolsista

do $\mathrm{CNPq}$ (I66032/20I5-8) e autora de Graciliano

Ramos e a Novidade: $o$ astrônomo do inferno e os

meninos impossiveis e, com Thiago Mio Salla,

de Conversas e Cangaços.

E-mail: biolito@gmail.com

\section{REFERÊNCIAS BIBLIOGRÁFICAS}

A AMÉRICA lê livros franceses impressos no Brasil. Diário Carioca, seção Homens, Livros e Ideias, Rio de Janeiro, 4 de outubro de 1942.

BICALHO, Ana Maria. Diálogos interculturais: Graciliano Ramos tradutor/traduzido. Tese (Doutorado em Letras e Linguística). Universidade Federal da Bahia, Instituto de Letras, Salvador, 2010.

BOSI, Alfredo. Reflexões sobre a arte. 4. ed. São Paulo: Ática, I99I. . Brás Cubas em três versões. São Paulo: Companhia das Letras, 2006.

. Machado de Assis na encruzilhada dos caminhos da crítica. Machado de Assis em Linha, ano 2, n. 4, dez. 2009.

BRAGA, Rubem. Velhas cartas; dezembro de I953. In: A traição das elegantes. Crônicas. Rio de Janeiro: Sabiá, I967, p. 45-8.

CARPEAUX, Otto Maria. Graciliano Ramos (No sétimo dia de sua morte). Correio da Manhã, Rio de Janeiro, 27 mar. I953.

DIAZ, Brigitte. O gênero epistolar ou o pensamento nômade: formas e funções da correspondência em

49 RÓNAI, Paulo. No mundo de Graciliano Ramos. In: Encontros com o Brasil, op. cit., p. 101. 
alguns percursos de escritores no século XIX. Tradução de Brigitte Hervot e Sandra Ferreira. São Paulo: Edusp, 2016.

DIAZ, José-Luis. Qual genética para as correspondências?. Tradução de Cláudio Hiro e Maria Sílvia Ianni Barsalini. Manuscrítica: Revista de Crítica Genética, I5. São Paulo, Associação de Pesquisadores de Crítica Genética/Humanitas, 2007, p. II9-I62.

ENCYCLOPÉDIE LAROUSSE en Ligne. Disponível em: <http://www.larousse.fr/encyclopedie/personnage/ Gallimard/IO33I2>. Acesso em: 30 abr. 2017.

GUIMARÃES, Hélio de Seixas. Os leitores de Machado de Assis: o romance machadiano e o público de literatura no século I9. 2. ed. São Paulo: Nankin/Edusp, 2012.

. Machado de Assis, o escritor que nos lê. As figuras machadianas através da crítica e das polêmicas. São Paulo: Editora Unesp, 2017.

HAROCHE-BOUZINAC, Geneviève. Escritas epistolares. Tradução de Ligia Fonseca Ferreira. São Paulo: Edusp, 2016.

MORAES, Marcos Antonio de. Edição da Correspondência Reunida de Mário de Andrade: histórico e alguns pressupostos. Patrimônio e Memória, Unesp/Assis - On-line, v. 4, p. I-I4, jun. 2009.

PAREYSON, Luigi. Os problemas da estética. Tradução de Maria Helena Nery Garcez. São Paulo: Martins Fontes, I997.

RAMOS, Graciliano. Infância. 3. ed. Rio de Janeiro: José Olympio, I953. . Linhas tortas. I4. ed. Rio de Janeiro: Record, I989. . Viventes das Alagoas. I9. ed. Rio de Janeiro: Record, 2007. . Cartas inéditas de Graciliano Ramos a seus tradutores argentinos Benjamín de Garay e Raúl Navarro. Introdução, ensaios e notas de Pedro Moacir Maia; organização e apresentação de Fernando da Rocha Peres. Salvador: Edufba, 2008.

. Cartas. Rio de Janeiro: Record, I980 (Edição especial; MPM-Comunicações); 7. ed. (aumentada). Rio de Janeiro: Record, I992. 8. ed., 20II.

. Discurso de Graciliano Ramos. In: Garranchos. Textos inéditos de Graciliano Ramos. Organização de Thiago Mio Salla. Rio de Janeiro: Record, 20I2, pp. 208-9. Conversas. Org. Thiago Mio Salla e Ieda Lebensztayn. Rio de Janeiro: Record, 2014.

RAMOS, Heloísa. Nota [Rio, out. I980]. In: RAMOS, Graciliano. Cartas. 8. ed. Rio de Janeiro: Record, 20II, p. 6.

RÓNAI, Paulo. O mundo de Graciliano. Correio da Manhã. Rio de Janeiro, 6 de junho de I948, p. 2-3. . No mundo de Graciliano Ramos. In: . Encontros com o Brasil. Rio de Janeiro: Instituto Nacional do Livro, I958.

. Como aprendi o português e outras aventuras. Rio de Janeiro: Casa da Palavra; Fundação Biblioteca Nacional, 20I3.

ROUYER-GAYETTE, François. Gallimard, I9IO-20II: un siècle d'édition. Bulletin des Bibliothèques de France $(B B F)$, 20II, n. 4, pp. 97-98. Disponível em: <goo.gl/Ll6Nci〉. Acesso em: 30 abr. 2017.

SALLA, Thiago Mio. Graciliano Ramos e a Cultura Política: mediação editorial e construção do sentido. São Paulo: Edusp/Fapesp, 2016.

SÉRIE CORRESPONDÊNCIA Ativa, Passiva e de Terceiros de Graciliano Ramos, Fundo Graciliano Ramos, Arquivo do Instituto de Estudos Brasileiros da Universidade de São Paulo, IEB-USP.

SODRÉ, Muniz. Georges Bernanos e o Brasil. A França no Brasil. Fundação Biblioteca Nacional, 2009. Disponível em: 〈goo.gl/IRNLU5>. Acesso em: 7 maio 2017.

SORÁ, Gustavo. Brasilianas: José Olympio e a gênese do mercado editorial brasileiro. São Paulo: Edusp: Com-Arte, 2010. 
STENDHAL. Vies de Haydn, de Mozart et de Métastase. Révision du texte et préface par Henri Martineau Paris: Le Divan, I8I4. Disponível em: <http://gallica.bnf.fr/ark:/I2I48/bpt6k6945I/fr.image.r=>. Acesso em: 25 jul. 2017.

SUPPO, Hugo Rogelio. La politique culturelle française au Brésil entre les années I920-I950. Tese (Doutorado). Villeneuve d'Ascq, França: Presses Universitaires du Septentrion, 2000. 3 v.

UMA INTERESSANTE iniciativa editorial. Dom Casmurro, Rio de Janeiro, I2 de setembro de I942, p. 6. UNIVERSIDADE DO PORTO. Faculdade de Letras. Biblioteca Digital. Disponível em: 〈goo.gl/YjP7OP〉. Acesso em: 30 abr. 20I7. 